\title{
Telomere processing in Euplotes
}

\author{
Joris R.Vermeesch, Dewight Williams and Carolyn M.Price* \\ Department of Chemistry, University of Nebraska-Lincoln, Lincoln, NE 68588-0304, USA
}

Received September 1, 1993; Revised and Accepted October 12, 1993

\begin{abstract}
In Euplotes crassus millions of telomeres are synthesized during the sexual phase of the life cycle. Since these newly synthesized telomeres are longer than normal macronuclear telomeres, they must be trimmed to the mature size. We have examined the timing and mechanism of this trimming step. We have shown that a sudden decrease in telomere length takes place at a specific time during macronuclear development. The decrease in telomere length is not caused by incomplete replication of the most terminal DNA sequences; rather it is the result of an active processing event that occurs independently of DNA replication. The developmentally regulated telomere shortening that takes place in Euplotes is reminiscent of the sudden reductions in telomere length which have been observed in other eukaryotes.
\end{abstract}

\section{INTRODUCTION}

Telomeres the DNA-protein complexes at the ends of chromosomes maintain chromosome integrity by preventing endto-end joining and ensuring complete replication of the most terminal DNA sequences (reviewed in 1 and 2). In many organisms telomeric DNA consists of tandem repeats of a 5-8 bp sequence. The total length of this repeated sequence DNA is regulated as the telomeres of most organisms exhibit a characteristic mean length. For example, telomeres from human sperm are usually $10-14 \mathrm{~kb}$ long (3) while Tetrahymena telomeres are $300-400$ bp (4). Telomere length regulation appears to be a complex process since genetic analysis has demonstrated the involvement of multiple alleles $(5,6)$. Expression of these various alleles produces factors that promote either shortening or lengthening of the telomeric DNA $(1,2)$. Final telomere length is determined by the balance between the lengthening and shortening activities (7).

Only some of the activities responsible for telomere shortening and lengthening have been identified. Gradual shortening of the chromosome can be caused by incomplete replication of the 5' terminus (8-11). Incomplete DNA replication is the inevitable consequence of a DNA polymerase that requires an RNA primer to initiate replication as removal of the RNA primer leaves an unreplicated region at the $5^{\prime}$ end of the daughter molecule $(1,2)$. Lengthening of telomeres is caused by the activity of telomerase $(12,13)$. Telomerase is a ribonucleoprotein enzyme that catalyzes the addition of telomeric repeats onto the $3^{\prime}$ terminus of the telomere. Addition of telomeric repeats by telomerase compensates for the telomere shortening that results from incomplete replication (14).

As the telomere lengthening and shortening activities are normally well balanced, telomere length generally only fluctuates slightly. However, sudden large decreases in telomere length are occasionally observed. When Trypanosomes or Tetrahymena are grown in $\log$ phase culture the telomeres lengthen until a certain maximum length is attained. At this stage some of the Trypanosome telomeres will under go a sudden shortening event so that telomere length is reduced by many $\mathrm{kb}(15,16)$. Sudden shortening of the extended Tetrahymena telomeres is observed if the cells are transferred from log phase to stationary phase culture conditions (4). Under the stationary phase conditions, all the telomeres quickly become $1000 \mathrm{bp}$ shorter. Rapid telomere shortening has also been observed in yeast when the telomerebinding protein RAP1 is mutated (17). Certain C-terminal truncations of RAP1 cause telomere length to increase by $\sim 4$ $\mathrm{kb}$. These extended telomeres are very unstable and undergo rapid but reversible deletion of large sections of the telomeric DNA.

Although incomplete replication seems to be the cause of gradual telomere shortening like that observed during the ageing of mammalian cells (18), this mechanism is unlikely to cause the rapid loss of large tracts of telomeric DNA. It has been proposed that sudden decreases in telomere length may arise as a result of either nuclease activity $(4,17)$ or recombination $(17,19)$. However, this hypothesis remains to be proven. In order to learn more about the mechanism of telomere shortening we have studied the developmentally controlled shortening event that takes place during sexual reproduction in Euplotes crassus.

Euplotes, like other ciliates, has two functionally and structurally distinct nuclei, the germline micronucleus and the vegetative macronucleus (20). The micronucleus contains $<100$ large chromosomes while the macronucleus contains millions of gene-sized pieces of DNA that have telomeres on each end (21). The length of the macronuclear telomeres is very tightly regulated as the vast majority consist of exactly 42 nucleotides of $T_{4} G_{4}$ sequence (22). The most internal 28 nucleotides of the telomere are double-stranded while the terminal 14 nucleotides form a $3^{\prime}$ overhang.

The macronucleus is generated from a copy of the micronucleus during the sexual phase of the life cycle (21). This process of macronuclear development takes about 100 hours and involves 
profound reorganization of the micronuclear DNA. Within the developing macronucleus (also called the anlagen) gene-sized molecules are excised from the micronuclear chromosomes and telomeres are added to each end. The residual non-coding sequences are destroyed. Although the newly synthesized telomeres consist of $\mathrm{C}_{4} \mathrm{~A}_{4}{ }_{4} \mathrm{G}_{4}$ sequence, they are both longer (by 46-48 nucleotides) and more heterogeneous in length than mature macronuclear telomeres $(23,24)$. During the final stage of macronuclear development, the newly generated macronuclear DNA molecules undergo several rounds of replication so that the average copy number is raised to $\sim 1000$ (21).

Since the newly synthesized telomeres are longer than mature macronuclear telomeres, generation of the mature telomeres must include a trimming step to remove the excess telomeric DNA $(23,24)$. We have investigated the timing and mechanism of this trimming step. Because so much DNA replication takes place at the end of macronuclear development, it was possible that trimming of the newly synthesized telomeres was a passive event that resulted from incomplete replication of the telomere ends. However, we have shown that this is not the case. Rather, telomere trimming occurs quite suddenly at a specific time during macronuclear development, and is an active processing event that occurs independently of DNA replication.

\section{MATERIALS AND METHODS}

\section{Culturing of Euplotes crassus}

Euplotes crassus was grown in septic culture using the algae Dunaliella salina as the food source $(25,26)$. Mass matings were performed as described (25) using the strains ST9 and ST11 (a gift from Dr L.Klobutcher). Dunaliella were grown until the culture reached an absorbance of 0.3 at $800 \mathrm{~nm}$. One-liter samples were then transferred to glass baking trays and inoculated with about $3 \times 10^{5}$ Euplotes cells. Two days after the Euplotes had eaten all the algae, equal volumes of each mating strain were mixed. The Euplotes were then returned to fresh baking trays and left to mate.

\section{Aphidicolin treatment of cell cultures}

Aphidicolin (provided by the Drug Synthesis and Chemistry Branch, Developmental Therapeutics Program, Division of Cancer Treatment, National Cancer Institute, National Institutes of Health, Bethesda, MD) was prepared as a $10 \mathrm{mg} / \mathrm{ml}$ stock solution in dimethylsulfoxide. To determine what concentration of aphidicolin was required to inhibit DNA replication and hence cell division, cultures of Euplotes crassus were grown in the presence of $5 \mu \mathrm{g}-100 \mu \mathrm{g}$ of the drug and the number of cells in each culture was determined on a daily basis. $50 \mu \mathrm{g} / \mathrm{ml}$ was found to inhibit cell division without causing cell death. To reduce the amount of aphidicolin needed for each experiment, the cells were concentrated 5-7 fold before addition of the drug. When anlagen were to be isolated, 3 liters of cells were concentrated to $600 \mathrm{ml}$ prior to the addition of aphidicolin. When total cellular DNA was to be isolated, 1 liter of cells was concentrated to 180 $\mathrm{ml}$ prior to the addition of aphidicolin. The cells were then cultured for the required length of time.

\section{Isolation of macronuclei, anlagen and macronuclear or} anlagen DNA

Mature macronuclei and anlagen were isolated as described previously $(24,25,27)$. To isolate anlagen, the cells were washed once with $40 \mathrm{ml}$ lysis solution (10 mM Tris, $2.5 \mathrm{mM} \mathrm{MgCl}_{2}$,
$\mathrm{pH}$ 7.5), pelleted at $750 \mathrm{~g}$, washed with $40 \mathrm{ml}$ lysis solution supplemented with $0.5 \%$ Triton X-100 and repelleted. A guanidinium thiocyanate solution (4 M guanidinium thiocyanate, $0.1 \mathrm{M}$ Tris, $\mathrm{pH} 7.5$ ) was added to the pellet and the cells were disrupted by sonication. The anlagen, which remained intact during this procedure, were pelleted at $3000 \mathrm{~g}$, resuspended in $10 \mathrm{ml}$ cold lysis solution and repelleted. The anlagen were then resuspended in $2 \mathrm{ml}$ of lysis solution, layered on $40 \mathrm{ml}$ of a $5 \%$ sucrose solution (10 mM Tris $\mathrm{pH} 7.2,2.5 \mathrm{mM} \mathrm{MgCl} 2,0.5 \%$ Triton $\mathrm{X}-100,5 \%$ sucrose) and centrifuged for 10 minutes at $3000 \mathrm{~g}$. This step was repeated once.

To isolate DNA, the anlagen were resuspended in $300 \mu \mathrm{l} \mathrm{TE}$ buffer (10 mM Tris, $1 \mathrm{mM}$ EDTA, $\mathrm{pH} 8.0)$ and heated to $70^{\circ} \mathrm{C}$ for 10 minutes, SDS was added to $0.5 \%$ and proteinase $\mathrm{K}$ to $200 \mu \mathrm{g} / \mathrm{ml}$. The sample was incubated at $56^{\circ} \mathrm{C}$ for 2 hours, phenol/chloroform extracted and ethanol precipitated. The DNA was then treated with RNAse A, phenol/chloroform extracted and ethanol precipitated. The DNA was quantified spectrophotometrically. A typical isolation provided 6-12 pg DNA/anlagen. To isolate DNA from whole cells, SDS , $\beta$ mercaptoethanol and EDTA were added to a cell preparation to final concentrations of $0.5 \%, 0.5 \mathrm{M}$ and $50 \mathrm{mM}$ respectively (26). The cell debris was ethanol precipitated, resuspended in TE buffer plus $0.5 \%$ SDS and the DNA isolated as described above.

\section{$3^{\prime}$ End-labeling of DNA, dimethyl sulfate modification and} guanine cleavage

To 3' end-label DNA with cordycepin, 1-2 $\mu \mathrm{g}$ ciliate DNA was incubated for 1 hour at $37^{\circ} \mathrm{C}$ with 1 pmol [ $\left.\alpha^{-32} \mathrm{P}\right]$ Cordycepin $(5000 \mathrm{Ci} / \mathrm{mmol} ; \mathrm{NEN})$ and 5 units of terminal deoxynucleotidyl transferase (Boehringer Mannheim) in a $15 \mu \mathrm{l}$ reaction containing $0.2 \mathrm{M}$ potassium cacodylate, $25 \mathrm{mM}$ Tris $\mathrm{pH} 6.6,25 \mathrm{mM}$ BSA. The labeled DNA was then phenol/chloroform extracted and ethanol precipitated.

Dimethylsulfate (DMS) modification and pyrrolidine cleavage were performed as described by Williamson et al. (28). Briefly, $1 \mu \mathrm{l}$ of a $1 / 100$ dilution of DMS was added to end-labeled DNA in $19 \mu \mathrm{l} \mathrm{H}_{2} \mathrm{O}$. After 10 minutes at $25^{\circ} \mathrm{C}$, the reaction was stopped by adding $20 \mu \mathrm{l} 2 \mathrm{M}$ pyrrolidine and heating the sample to $90^{\circ} \mathrm{C}$ for 15 minutes. The DNA fragments were separated on $8 \%$ or $20 \%$ polyacrylamide sequencing gels. A sodium acetate salt gradient ( $250 \mathrm{mM}$ in bottom chamber) was used to improve the resolution (29).

Purified anlagen DNA was used to examine telomere length during macronuclear development so as to avoid contamination with old macronuclear DNA molecules (24). However, whole cell DNA was used in experiments looking at telomere length in vegetative cells or newly developed macronuclei. In these cells macronuclear telomeres are in vast excess over micronuclear telomeres and in the fully developed cells all the old macronuclear DNA fragments are gone.

\section{Southern blot hybridization}

DNA was separated on 0.8 to $1.2 \%$ agarose gels, transferred to nylon membrane (MSI) using a vacuum blot apparatus (Pharmacia) and fixed to the membrane by baking at $80^{\circ} \mathrm{C}$ for 2 hours (30). $7 \mu \mathrm{g}$ anlagen DNA or whole cellular DNA, or 3 $\mu \mathrm{g}$ macronuclear DNA was loaded per lane. Prior to transfer, the gel was treated for 15 minutes each with a depurination solution $(0.25 \mathrm{~N} \mathrm{HCl})$, a denaturation solution $(1.5 \mathrm{M} \mathrm{NaCl}, 0.5$ $\mathrm{M} \mathrm{NaOH})$, and a neutralization solution (1 M Tris, $2 \mathrm{M} \mathrm{NaCl}$ ). 
The transfer was performed in $10 \times$ SSC for 1 hour. The filters were incubated overnight with a $5^{\prime}$ end-labeled 64 base oligonucleotide $\left(\left(\mathrm{G}_{4} \mathrm{~T}_{4}\right)_{8}\right)$ at $46^{\circ} \mathrm{C}$ in $400 \mathrm{mM} \mathrm{NaCl}, 10 \mathrm{mM}$ Tris pH 8.0, $1 \mathrm{mM}$ EDTA, $50 \%$ formamide, $0.1 \%$ SDS and $5 \times$ Denhardt's solution, and then washed 3 times for 20 minutes at $66^{\circ} \mathrm{C}$ with $0.1 \% \mathrm{SSC}$ and $0.2 \%$ SDS. These conditions allowed the probe to hybridize to oversized but not mature length telomeres. The signal intensity was measured with an AMBIS 1000 radioanalytic imaging detector (AMBIS Inc, San Diego, CA).

\section{Examination of nuclear morphology}

Cells were fixed in sea water plus 5\% formaldehyde for 15 minutes, concentrated by centrifugation (100 g for 3 minutes), and rinsed 3 times with phosphate buffered saline $(140 \mathrm{mM} \mathrm{NaCl}$, $10 \mathrm{mM} \mathrm{Na}_{2} \mathrm{HPO}_{4}, 1 \mathrm{mM} \mathrm{NaH} \mathrm{PO}_{4}, \mathrm{pH}$ 7.2). The cells were then incubated with $1 \mu \mathrm{l} / \mathrm{ml}$ Hoechst dye (\#33342) for $30 \mathrm{~min}$, rinsed 3 times with phosphate buffered saline and examined by fluorescence microscopy.

\section{RESULTS}

\section{The timing of telomere trimming}

When Roth and Prescott discovered that newly synthesized Euplotes telomeres are longer than mature macronuclear telomeres, they suggested that trimming of the long telomeres occurs during the final stages of macronuclear development $(21,23)$. To confirm this premise, we examined the length of telomeric DNA from cells that had just completed macronuclear development. Telomere length was visualized by $3^{\prime}$ end-labeling macronuclear DNA with ${ }^{32} \mathrm{P}$-cordycepin, methylating the DNA with dimethylsulfate (DMS) and treating it with pyrrolidine to

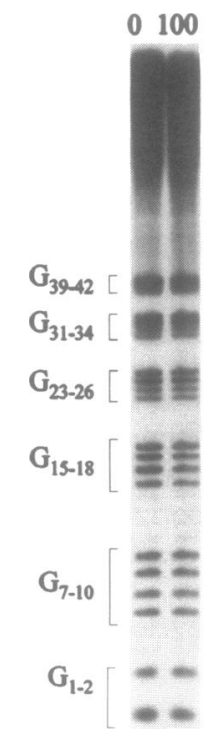

Figure 1. Examination of telomere length immediately following macronuclear maturation. Total cellular DNA isolated either before (marked 0 ) or 100 hours after the initiation of the mating (marked 100 ), was $3^{\prime}$ end-labeled with ${ }^{32} \mathrm{P}$ cordycepin, modified with DMS, cleaved at methylated guanines and separated on a sequencing gel. The positions of the guanines relative to the $3^{\prime}$ terminus are marked at the side of the gel. The bracket on the right indicates where extra G-repeats would be observed if a significant fraction of the telomeres were oversized. cleave at the modified $\mathrm{G}$ residues. When the resulting DNA fragments were separated on a sequencing gel, the $\mathrm{T}_{4} \mathrm{G}_{4}$ sequence of the telomeric DNA was apparent as a series of $\mathrm{G}_{4}$ repeats extending up the gel. For DNA isolated from cells at the end of macronuclear development ( 100 hours after initiating mating) the $\mathrm{G}_{4}$-repeat pattern extended only 42 nucleotides and was generally indistinguishable from the pattern obtained with DNA from unmated cells (Figure 1). Since newly synthesized telomeres give rise to $\mathrm{a}_{4}$-repeat pattern that extends for $\sim 98$ nucleotides (28, and see Figure 3a), this finding demonstrated that telomere trimming had taken place. By 100 hours after mating, Euplotes cells have developed mature horseshoe shaped macronuclei. However, the cells have not yet undergone any vegetative divisions. Thus, our results confirm Roth and Prescott's premise that trimming of the oversized telomeres occurs during late macronuclear development rather than during subsequent cell divisions. Since multiple rounds of DNA replication take place during late macronuclear development, it was conceivable that trimming of the telomeres results from incomplete replication of the telomere ends during these rounds of replication. To explore this possibility, we determined the timing of telomere trimming more precisely. Anlagen (developing macronuclei) were isolated at various times after telomere addition (ie. after $\sim 60$ hours) and then monitored for the appearance of mature length telomeres. As the rate at which cells proceed through macronuclear development fluctuates slightly from mating to mating, we used the morphology of the developing macronuclei to assess the developmental stage of the culture (31). During late macronuclear development the round anlagen elongate until they reach the horseshoe shape characteristic of mature macronuclei. Anlagen elongation is a particularly useful developmental marker as previous studies have demonstrated that DNA replication takes place during the elongation phase $(23,32,33)$. Examples of round and elongating anlagen and mature macronuclei are illustrated in Figure 2.

Anlagen were isolated at $65,70,75$ and 85 hours after the onset of mating, the anlagen DNA was purified, 3 ' end-labeled

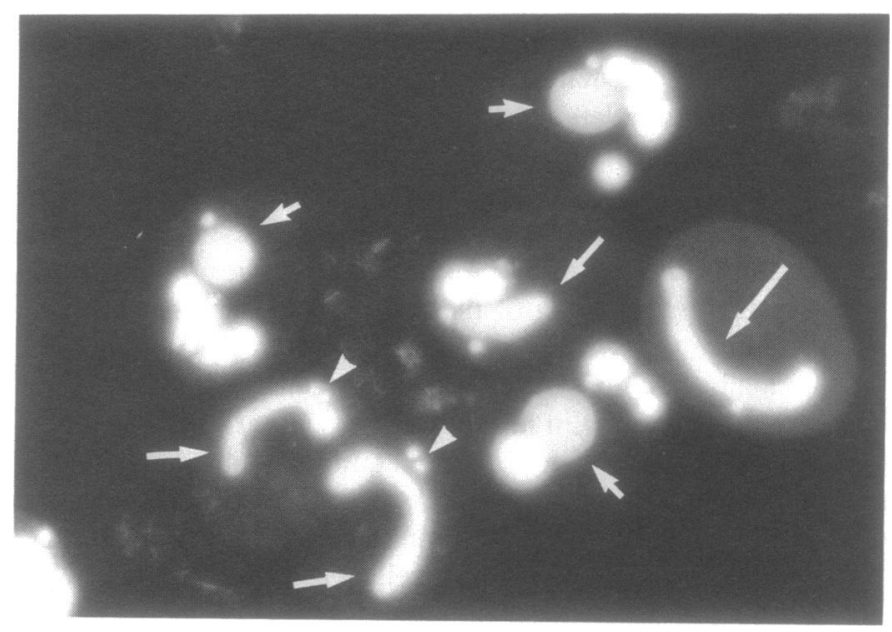

Figure 2. Fluorescent microscopy of cells in the final stages of macronuclear development. Cells at 80 hours of development were fixed with $5 \%$ formaldehyde and stained with Hoechst dye. Examples of round anlagen, elongating anlagen, and mature macronuclei are marked with short, medium length and long arrows respectively. Micronuclei are marked by arrowheads. The large unmarked objects are fragments of the old macronucleus. 
A

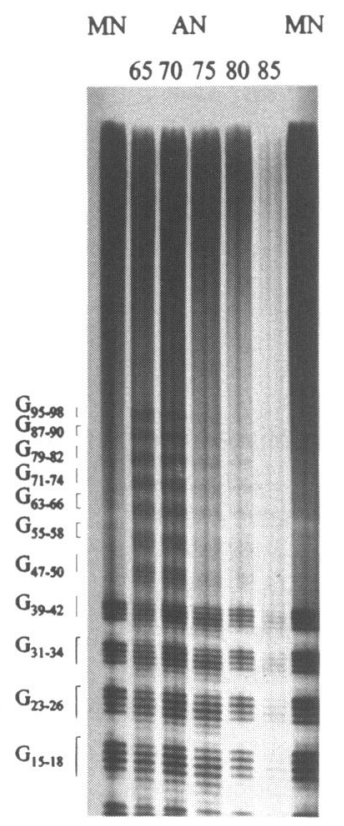

B

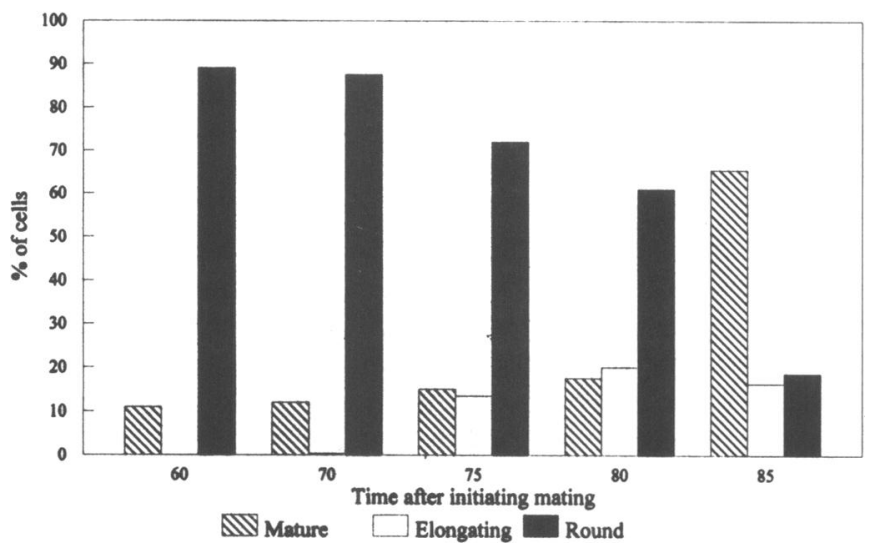

Figure 3. Examination of telomere length during the final stages of macronuclear development. (A) The G-cleavage pattern of anlagen DNA isolated at various times after initiating mating. The anlagen DNA was labeled with ${ }^{32} \mathrm{P}$-cordycepin, modified with DMS and cleaved at methylated guanines. The positions of the guanines relative to the $3^{\prime}$ terminus are marked to the side of each gel. The time of anlagen isolation is indicated at the top of each lane. MN, macronuclear DNA; AN, anlagen DNA. (B) The progression of the cell culture through development. Cells were fixed with 5\% formaldehyde and stained with Hoechst dye. The percent of cells having mature horseshoe shaped macronuclei, elongating anlagen, and round anlagen was then determined for each time point.

with cordycepin, methylated with DMS and cleaved with pyrrolidine. The DNA fragments were then separated on an $8 \%$ sequencing gel. As shown in Figure 3a, at 65 hours of development the $\mathrm{G}_{4}$-repeat pattern extended $\sim 98$ nucleotides up the gel. Thus, at this time all the telomeres were oversized. At 70 hours, trimming of the telomeres seemed to have just started as there was a slight decrease in the intensity of the G-cleavage pattern between $G_{39-42}$ and $G_{47-50}$. This change in intensity indicated that some telomeres now terminated after only 42 nucleotides. By 75 hours most of the telomeres had been trimmed as the length of the $G_{4}$-repeat pattern had decreased to 42 nucleotides for the majority of the DNA molecules. These results
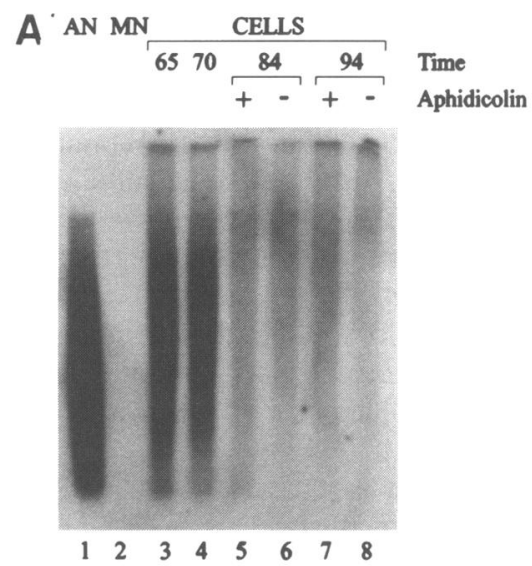

B

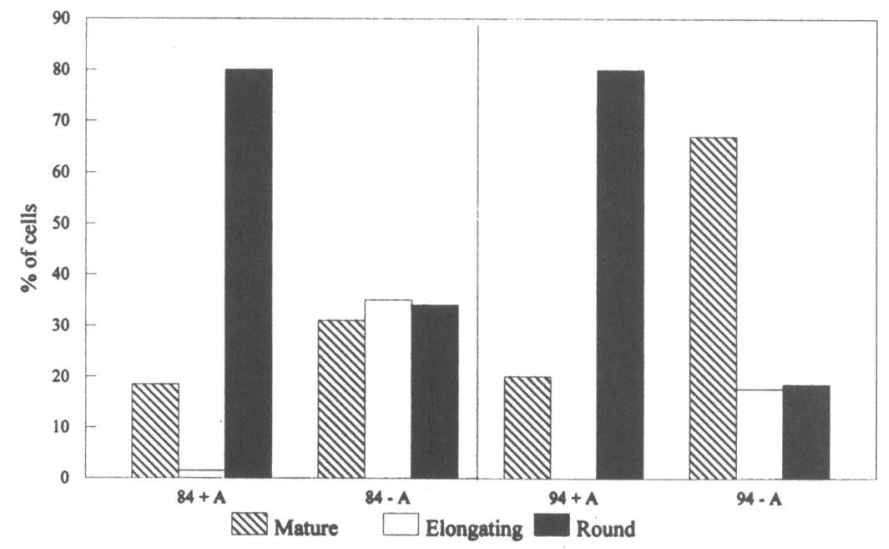

Figure 4. Detection of telomere trimming following growth in aphidicolin. (A) Southern blot probed with $\left(\mathrm{G}_{4} \mathrm{~T}_{4}\right)_{8}$ using conditions that detect oversized but not mature length telomeres. AN, DNA from anlagen isolated at 65 hours. MN, macronuclear DNA. CELLS, total cellular DNA. The time of cellular DNA isolation is indicated above the lanes; + and - indicate the presence or absence of aphidicolin. (B) Histogram representing the fraction of cells displaying mature horseshoe shaped macronuclei, elongating anlagen, and round anlagen following growth in the presence or absence of aphidicolin.

indicate that trimming of the oversized telomeres occurs quite suddenly.

Two lines of evidence indicate that this sudden shortening occurs just prior to anlagen elongation. First, the guanidinium thiocyanate-based protocol used to isolate anlagen only resulted in the isolation of anlagen that were still at the round stage. The guanidinium lyses mature macronuclei and anlagen that have started to elongate (J.Vermeesch and D.Williams, unpublished results). Second, examination of the nuclear morphology of the cultures used to isolate anlagen revealed that for most cells anlagen elongation did not occur until after telomere trimming had taken place. As shown in Figure 3b, almost none of the anlagen had started to elongate at 70 hours when trimming was first observed and by $\mathbf{7 5}$ hours when trimming was essentially complete, $<15 \%$ had entered the elongation phase.

\section{Telomere processing is DNA replication independent}

While the previous experiment indicated that telomere trimming occurs prior to anlagen elongation, it did not completely exclude the involvement of DNA replication in the trimming process. 
Since it has not been determined exactly when replication starts relative to anlagen elongation, it remained possible that trimming of the oversized telomeres occurred in tandem with the first rounds of replication. To ascertain whether trimming is dependent on DNA replication, we used the drug aphidicolin to inhibit replication during the final stages of macronuclear development. We then determined whether or not telomere trimming had taken place. In this experiment, the telomeres of aphidicolin treated cells should remain oversized if telomere trimming is dependent on DNA replication. However, if trimming is a replication independent event the aphidicolin treatment should not prevent the appearance of short telomeres.

We used two different methods to detect long versus short telomeres. Initially we 3' end labeled anlagen DNA, treated with DMS, cleaved at G-residues and separated the resulting fragments on sequencing gels to assess the length of the G-repeat pattern (data not shown). In later experiments we used a hybridization assay to detect long but not short telomeres (Figure 4a, (34)). For this assay, Southern hybridization conditions were developed that allowed a 64 nucleotide $\left(\mathrm{T}_{4} \mathrm{G}_{4}\right)_{8}$ probe to hybridize to stretches of $\mathrm{C}_{4} \mathrm{~A}_{4}$ that were longer than 32 nucleotides (the length of the $\mathrm{C}$-rich strand of a mature telomere). As shown in Figure 4a, lanes 1 and 2, these hybridization conditions permitted efficient detection of molecules with long but not mature length telomeres. The hybridization assay had the advantage of being able to detect all of the oversized telomeres at one time. This was not possible using the direct end-labeling assay due to the preference of terminal transferase for molecules that have guanines at the $3^{\prime}$ terminus (24). As the oversized telomeres terminate in thymidines as well as guanines only a portion of the telomeres are end-labeled.

Aphidicolin was added to cell cultures at 70 hours after the initiation of mating. The cells were then isolated either 14 hours later (ie. at 84 hours after mating) or 24 hours later (ie. at 94 hours after mating) and total cellular DNA was prepared. DNA was also prepared from cells at 65 and 70 hours after mating, and at 84 and 94 hours from control cultures that were not treated with aphidicolin. To determine whether the DNA from the aphidicolin treated and control cells had undergone telomere shortening, the DNA was blotted to nylon membrane and hybridized with the $\left(\mathrm{G}_{4} \mathrm{~T}_{4}\right)_{8}$ probe. As expected, the DNA isolated at 65 hours (Figure $4 \mathrm{a}$, lane 3 ) gave rise to a strong hybridization signal. However, by 84 hours the intensity of the signal had decreased greatly in both the aphidicolin treated and untreated cells (lanes 5 and 6). This finding indicates that the aphidicolin treatment had little affect on trimming of the oversized telomeres. When telomere length was assayed by the direct endlabeling method we obtained a similar result (data not shown). Thus, our data suggest that telomere trimming is a specific processing step that occurs independently of DNA replication.

Quantitation of the hybridization signals revealed that about $25 \%$ of the telomeres were processed between 65 and 70 hours while $50 \%$ were processed between 70 and 84 hours. Little processing occurred after 84 hours. The residual hybridization signal seen at 84 and 94 hours probably reflects the failure of some cells to complete macronuclear development. Even in the absence of aphidicolin a significant number of cells (up to $\sim 20 \%$ ) arrest at the round anlagen stage (see Figure $4 b$ ).

To ensure that the aphidicolin was entering the cells and having an effect on macronuclear development, we determined fraction of cells containing either round anlagen, elongating anlagen or mature macronuclei at the time of anlagen isolation. As can be seen from Figure $4 b$, virtually all the aphidicolin treated cells remained in the round anlagen phase while the untreated cells entered the elongation phase normally and eventually matured. Thus, the aphidicolin treatment blocked cell development even though telomere processing was unaffected. These results clearly demonstrate that telomere processing in Euplotes occurs prior to anlagen elongation in a replication independent event.

\section{DISCUSSION}

While it is now well established that telomere length is determined by a balance between factors that promote shortening and lengthening of the telomeric DNA, only some of the shortening and lengthening activities have been identified. In order to learn more about the mechanism of telomere shortening, we have analyzed the telomere processing event that occurs following de novo telomere synthesis in Euplotes crassus.

We have shown that trimming of the oversized telomeres to the mature size occurs quite suddenly at a well defined time during macronuclear development. As a result of this event, the majority of the telomeres in the developing macronuclei undergo a concomitant reduction in size with the G-strands decreasing from an average of 89-95 nucleotides to 42 nucleotides in length. Trimming of the telomeres occurs even in the presence of aphidicolin, a drug that blocks DNA replication in most eukaryotes including Euplotes (35-37). Thus, the reduction in telomere length can not merely arise as a result of incomplete replication of the chromosome termini during the rounds of DNA replication that take place at the end of macronuclear development. Rather, trimming of the telomeres appears to be an active processing event that is completely independent of DNA replication. The telomere shortening that we have observed in Euplotes is reminiscent of the sudden drop in telomere length that has been observed when log phase cultures of Tetrahymena thermophila enter stationary phase. At this time, the telomeres of all the Tetrahymena undergo a simultaneous decrease in length (4). The Euplotes telomere processing may also be related to the sudden telomere shortening events that have been observed in other organisms such as trypanosomes and yeast $(15-17)$.

While we can say with certainty that Euplotes telomeres are subject to an active processing event, the mechanism of this event remains to be determined. Although it has been suggested that sudden telomere shortening may be caused by recombination $(17,19)$, it seems unlikely that this process is responsible for the shortening of Euplotes telomeres. In organisms such as yeast which have long tracts of telomeric DNA, it is not difficult to envision how random recombination events might cause a sudden drop in the length of one or more telomeres (17). However, it is very difficult to visualize how recombination could cause the coordinate shortening of all telomeres by $\sim 52$ nucleotides to give a final telomere length of precisely 42 nucleotides. The simplest way to account for the precise telomere processing that occurs in Euplotes is via the activity of a nuclease. This nuclease could be either a exonuclease or an endonuclease. An endonuclease might cut within the telomeric tract to remove the excess telomeric DNA while an exonuclease could nibble in from the end. Whether or not this nuclease would have to be a special 'telomere nuclease' is unclear. However, given that a very wide variety of different processing events require the activity of a specific nuclease (eg tRNA processing, poly A tail removal, G-quartet removal, etc.) a special telomere nuclease could well exist $(38-40)$. 
Regardless of how the excess DNA is removed during processing of Euplotes telomeres, there must be a mechanism for ensuring that the correct number of nucleotides of telomeric DNA are retained. Thus, it is likely that length-determining factor(s) exist which protect a certain length of telomeric DNA and/or regulate telomerase activity. The processed telomeres have the organization characteristic of mature telomeres (i.e. $28 \mathrm{bp}$ double-stranded telomeric DNA and a 14 nucleotide $T_{4} G_{4} T_{4} G_{2}$ $3^{\prime}$ single-stranded overhang). To attain this very precise organization it is likely that the mechanism for telomere shortening acts in concert with the length-regulating mechanism that is active during vegetative growth. Although the identity of the telomere length-regulating factor(s) is unknown, several candidate molecules have been identified. One candidate is the $51 \mathrm{kDa}$ telomere-binding protein. As this protein binds tightly to mature macronuclear telomeres it has been postulated to play a role in telomere length regulation $(26,27,41,42)$. The telomere protein homolog is another possible length-regulating factor. This protein has extensive homology to the DNA-binding domain of the telomere-binding protein but its function is unknown (43). Interestingly, the homolog protein is present in replication bands in vegetative cells and is expressed during the elongation phase of macronuclear development (W.Wang and C.Price, manuscript in preparation).

Until now biochemical studies of telomere shortening have been difficult to perform because in most organisms the sudden shortening events occur quite randomly. However, investigation of this phenomenon should be facilitated by our finding that processing of Euplotes telomeres is an active event that occurs at a well defined time during macronuclear development. Understanding the mechanism of telomere processing in Euplotes is likely to lead to a better understanding of telomere dynamics in other organisms.

\section{ACKNOWLEDGEMENTS}

We thank Julie Bartos for assistance with growing Euplotes crassus, Scott Perez for assistance with the figures and Dorothy Shippen for critical reading of the manuscript. This research was supported by the National Institutes of Health grant GM41803 and by an American Cancer Society Junior Faculty Research Award to CMP.

\section{REFERENCES}

1. Zakian, V. A. (1989) Ann. Rev. Genet., 23, 579-604.

2. Biessmann, H., and Mason, J. M. (1992) Adv. Genet., 30, 185-249.

3. deLange, T., Shiue, L., Myers, R. M., Cox, D. R., Naylor, S. L., Killery, A. M., and Varmus, H. E. (1990) Mol. Cell. Biol., 10, 518-527.

4. Larson, D. D., Spangler, E. S., and Blackburn, E. H. (1987) Cell, 50, 477-483.

5. Burr B., Burr, F. A., Matz, E. C., and Romero-Severson, J. (1992) The Plant Cell, 4, 953-960.

6. Walmsley, R. M., and Petes, T. D. (1985) Proc. Natl. Acad. Sci. USA, $82,506-510$

7. Shampay, J., and Blackburn, E. B. (1988) Proc. Natl. Acad. Sci. USA, 85, $534-538$

8. Biessmann, H., and Mason, J. M. (1988) EMBO J., 7, 1081-1086.

9. Levis, R. W. (1989) Cell 59, 791-801.

10. Biessmann, H., Carter, S. B., and Mason, J. M. (1990) Proc. Natl. Acad. Sci. USA, 85, 1758-1761.

11. Harley, C. B., Futcher, A. B., and Greider, C. W. (1990) Nature, 345, 458-460.

12. Greider, C. W., and Blackburn, E. H. (1989) Cell, 51, 887-898.

13. Blackburn, E. (1993). Ann. Rev. Biochem., 61, 113-129.
14. Blackburn, E. (1991) TIBS, 16, 378-381.

15. Pays, E., Laurent, M., Delinte, K., Van Meirvenne, N., and Steinert, M. (1983) Nuc. Acids Res., 11, 8137-8141.

16. Bernards, A., Michels, P. A. M., Lincke, C. R., and Borst, P. (1983) Nature, 303, 592-597.

17. Kyrion, G., Boakye, K. E., and Lustig, A. J. (1992) Mol. Cell. Biol., 12, 5159-5173.

18. Counter, C. M., Avilion, A. A., LeFeuvre, C. E., Stewart, N. G., Greider, C. W., Harley, C. B., and Bacchetti, S. (1992) EMBO J., 11, 1921-1929.

19. Conrad, M. N., Wright, J. H., Wolf, A. J., and Zakian, V. H. (1990). Cell, 63, 739-750.

20. Raikov, I. B. (1982). The protozoan nucleus, morphology and evolution. Springer-Verlag, Wein, New York.

21. Klobutcher, L. A., and Prescott, D. M. (1986) In Gall, J. G. (ed.), The special case of the Hypotrichs. The molecular biology of ciliated Protozoa., Academic Press, pp. 111-154.

22. Klobutcher, L. A., Swanton, M. T., Donini, P., and Prescott, D. M. (1981) Proc. Natl. Acad. Sci. USA, 78, 3015-3019.

23. Roth M., and Prescott, D. M. (1985) Cell, 67, 807-814.

24. Vermeesch, J. R., and Price, C. M. (1993) Manuscript accepted pending revision.

25. Roth, M., Lin, M., and Prescott, D. M. (1985) J. Cell Biol., 101, 79-84.

26. Price, C. M. (1990) Mol. Cell. Biol., 10, 3421-3431.

27. Price, C. M., Skopp, R., Krueger, J., and Williams, D. (1992) Biochemistry, $31,10835-10843$.

28. Williamson, J. R., Raghuraman, M. K., and Cech, T. R. (1989) Cell, 59, $871-880$.

29. Sheen J.-Y., and Seed, B. (1988) Biotechniques, 6, 942-944.

30. Sambrook, J., Fritsch, E. F., and Maniatis, T. (1989) Molecular Cloning: A laboratory manual. Cold Spring Harbor University Press. Cold Spring Harbor.

31. Price, C. M., Adams, A. K., and Vermeesch, J. R. (1993) Mol. Cell. Biol. Manuscript submitted.

32. Rao, N. M. V. (1968) Exp. Cell. Res., 49, 411-419.

33. Rao, N. M. V., and Ammermann, D. (1970) Chromosoma, 29, 246-254

34. Klobutcher, L. A., Turner, L. R., and Peralta, M. E. (1991) J. Protozool., $34,425-427$.

35. Spadari, S., Sala, F., and Pedrali-Noy, G. (1982) TIBS, 7, 29-32.

36. Sheaff, R., Isley, D., and Kuchta, R. (1991) Biochemistry, 30, 8590-8597.

37. Olins, D. E., and Olins, A. L. (1993) J. Euk. Microbiol., 40, 459-467.

38. Darr, S. C., Brown, J. W., and Pace, N. R. (1992). TIBS, 17, 178-182.

39. Peltz, S. W., and Jacobson, A. (1992) Curr. Opin. Cell Biol., 4, 979-983.

40. Liu, Z., Frantz, J. D., Gilbert, W., and Tye B.-K. (1993) Proc. Natl. Acad. Sci. USA, 90, 3157-3161.

41. Raghuraman, M. K., Dunn, C. J., Hicke, B. J., and Cech, T. R. (1989) Nucl. Acids Res., 17, 4235-4253.

42. Yu, G.-L., Bradley, J. D., Attardi, L. D., and Blackburn, E. H. (1990) Nature, 344, 126-132.

43. Wang, W., Skopp, R., Scofield, M., and Price, C. M. (1992) Nucl. Acids Res., 20, 6621-6629. 